\title{
A Practice-based Approach to Collective Decision-making in Pricing
}

Thrane, Sof; Jarmatz, Martin; Laursen, Michael Fetahi; Kornmaaler, Katrine

\author{
Document Version \\ Accepted author manuscript \\ Published in: \\ Qualitative Research in Accounting \& Management
}

DOI:

10.1108/QRAM-03-2018-0019

Publication date:

2019

License

Unspecified

Citation for published version (APA):

Thrane, S., Jarmatz, M., Laursen, M. F., \& Kornmaaler, K. (2019). A Practice-based Approach to Collective Decision-making in Pricing. Qualitative Research in Accounting \& Management, 16(1), 117-143.

https://doi.org/10.1108/QRAM-03-2018-0019

Link to publication in CBS Research Portal

\section{General rights}

Copyright and moral rights for the publications made accessible in the public portal are retained by the authors and/or other copyright owners and it is a condition of accessing publications that users recognise and abide by the legal requirements associated with these rights.

\section{Take down policy}

If you believe that this document breaches copyright please contact us (research.lib@cbs.dk) providing details, and we will remove access to the work immediately and investigate your claim. 


\title{
A Practice-based Approach to Collective Decision-making in Pricing
}

\section{Sof Thrane, Martin Jarmatz, Michael Fetahi Laursen, and Katrine Kornmaaler}

\author{
Journal article (Accepted manuscript*)
}

\section{Please cite this article as:}

Thrane, S., Jarmatz, M., Laursen, M. F., \& Kornmaaler, K. (2019). A Practice-based Approach to Collective Decision-making in Pricing. Qualitative Research in Accounting \& Management, 16(1), 117-143.

https://doi.org/10.1108/QRAM-03-2018-0019

\section{DOI: https://doi.org/10.1108/QRAM-03-2018-0019}

This article is [- Emerald Group Publishing and permission has been granted for this version to appear here: https://research.cbs.dk/en/publications/a-practice-based-approach-to-collective-decision-making-in-pricin

Emerald does not grant permission for this article to be further copied/distributed or hosted elsewhere without the express permission from Emerald Group Publishing Limited.

* This version of the article has been accepted for publication and undergone full peer review but has not been through the copyediting, typesetting, pagination and proofreading process, which may lead to differences between this version and the publisher's final version AKA Version of Record. 


\title{
A practice-based approach to collective decision-making in pricing
}

\author{
Sof Thrane \\ Martin Jarmatz \\ Michael Fetahi Laursen \\ Katrine Fabritius Kornmaaler \\ In review Qualitative Research in Accounting and Management
}

\begin{abstract}
Purpose - The objective of this paper is to analyze price decision-making through a practice-based approach. The paper investigates the micro-level practices used to arrive at sales price decisions.

Design/methodology/approach - In this study a qualitative study approach is used to develop findings abductively. The data are gathered through an in-depth case study at two firms: semi-structured interviews, meeting observations, shadowing and pricing documents.
\end{abstract}

Findings - This paper finds that pricing is a collective decision-making process involving multiple actors across the organization. The case firms work on solving information, coordination and control problems to arrive at sales prices by enacting interlinked practices. Pricing is therefore neither a structure nor a single decision but a process consisting of multiple micro-level practices that enable firms to make pricing decisions.

Originality/value - This paper develops a practice-based approach to pricing studies how micro-level practices enable firms to make decisions in spite of the numerous challenges encountered in pricing processes. The paper is interdisciplinary and adds to the accounting and market literatures, which have tended to study pricing as a decision made by one decision maker, and not as an organizational process where multiple actors share, evaluate, interpret and coordinate information and decisions.

Keywords Pricing practice, behavioral pricing, price decision-making, information-processing, pricing control. 


\section{Introduction}

Setting the right price is an important task for an organization because it has a major direct effect on profits (Hinterhuber and Liozu, 2012). Pricing however is a complex task that involves multiple parts of the organization (Dutta et al., 2003). For instance, it is dependent on learning from the market (Bloomfield and Luft, 2006) and on the intelligent use of cost data (Cardinaels et al., 2004). Pricing, further, often must be dynamic and must consider unforeseen events (Ellström and Larsson, 2017).

This complexity generates three problems in the management of pricing decisions. First, there is an information-processing problem. Pricing information is difficult to evaluate because customer information is incomplete and uncertain (Anderson et al., 2007; Spender, 1989) and cost information may bias decisions (Bloomfield and Luft, 2006). Second, there is a coordination problem because the pricing decision must account for information about capacity, cost, customers, strategies and so forth, and this information involves employees located in different departments and geographies. The disparate sets of information may affect the profitability of pricing decisions and therefore should be transferred and collocated. Third, pricing is subject to a control problem. The interests of the different parties affecting pricing decisions, such as sales, the pricing function, production, and marketing, are often not aligned and lead to decisions that potentially reduce firm profitability. These problems have been analyzed from two overarching perspectives: the accounting and control view, and the market view.

The accounting and control literature focuses on the decentralization level of pricing decisions and the use of cost information in the pricing process. One stream of research investigates how different types of cost information (activity-based and full cost) affect pricing decisions (Cardinaels et al., 2004; Drake and Haka, 2008; Hsu, 2011; Lucas, 2003; Van den Abbeele et al., 2009) and how cost information may affect firms' ability to learn from the market (Bloomfield and Luft, 2006). A second approach investigates the optimal level of decentralization to the sales force, given that sales have superior knowledge of customers but may have interests that are not aligned with strategic objectives (Balan, 2016; Homburg et al., 2012; Jensen and Meckling, 1995). The accounting and control view generally employs experimental, survey or modelling based approaches to develop optimal levels of decentralization and use of different types of cost data. This neglects the control processes and practices through which situated actors use cost information, coordinate and generate accountability for pricing decisions. A perspective that considers processes of organizing can extend this research.

The market view focuses on identifying which information - customer value, cost or competitor - to use in the pricing decision and on how this information is processed. According to the market view, using market information about customers' value perceptions yields superior results (Hinterhuber, 2004; Ingenbleek et al., 2003; Ingenbleek and van der Lans, 2013). Also according to this approach, the use of intuition or rational processing of pricing information has differential impacts on decision quality (Iyer et al., 2015; Kahneman and Klein, 2009;). The market view, however, can be extended in many ways. While there are a few notable exceptions (e.g. Zbaracki and Bergen, 2010), the literature historically views the pricing decision as being performed by one individual who processes customer information either intuitionally or rationally. It therefore de-emphasizes the processes and 
practices through which the multiple organizational entities that possess pricing-relevant information interact, share, and interpret information.

In this paper we employ an interdisciplinary, practice-based approach that draws on both the market and the accounting literatures to explore firms' pricing processes. A practicebased approach to pricing takes practices as the unit of analysis (Nicolini and Monteiro, 2017). The approach focuses on the informal, routinized patterns of interactions and activities that compose pricing processes. However, this approach considers processes - such as pricing decision-making - as a social, not an individual, matter. Thus, we respond to calls for further studies on the micro-foundations and behavioral aspects of pricing and to claims that the literature does not provide "sufficient detail to understand how companies organize for pricing” (Carricano et al., 2010, p. 468). Specifically, this paper examines the following research question:

$R Q$. How are pricing practices interlinked in the process of making sales price decisions?

We investigate this research question through analysis of two case studies of the business-to-business (B2B) pricing process. Our analysis shows that four practices are used in pricing decision-making: information-processing, interaction with the pricing system, communication, and accountability and control practices. Actors employ these practices to address information, coordination and control problems, ultimately reducing complexity. A pricing decision then results from the numerous interlinked practices that enable organizational actors to process relevant information, coordinate the multiple actors involved in the process and control pricing decisions.

With its development of an interdisciplinary, practice-based approach to pricing, this paper contributes to existing pricing research in four ways. First, by generating a detailed overview of micro-level practices, we suggest that pricing is a complex organizational process made of multiple interlinked practices and their inherent activities. Second, we extend the extant literature's focus on how individuals process information by illustrating that the actor's intuitive and rational processing of cost and value information depends on and is interlinked with other activities and practices. Information is processed at multiple stages before a pricing decision is made. Third, we illustrate how the delegation of pricing authority is not just a structure of clearly defined decisions rights. Accountability structures are based on interactions in which relations of authority are sometimes blurry and become defined in processes. Fourth, access to cost and capacity information is not dichotomous - either present, biasing decisions (Bloomfield and Luft, 2006), or absent, reducing profits (Cardinaels et al., 2004). Different entities have different access to cost information, and their interaction determines how cost information affects decisions.

The paper is structured as follows. In Section 2, we develop the three problems of pricing and discuss our approach to studying pricing practices. In Section 3, we present the research methods including the four pricing practices. In Sections 4 and 5, we analyze how pricing practices are used by looking at the pricing processes of two firms. Finally, in Section 6 we discuss the findings and offer conclusions. 


\section{Review of literature}

\subsection{Information, coordination and control problems in pricing}

In the following, we develop the three pricing problems, drawing on both the market and the accounting and control literatures. The information problem is caused by difficulties in evaluating pricing-relevant information. Customer value information is incomplete and uncertain because customers are seldom willing to disclose their willingness to pay (Anderson et al., 2007; Spender, 1989). Dutta et al. (2003) noted that firms "face considerable uncertainty about the price elasticity and the relative profitability of these different groups of customers” (p. 628). Competitor information is often inaccurate because the discounts given off known list prices vary greatly, and these are often not part of published price catalogs but negotiated individually with the customer. Also, when salespeople aim to collect competitive pricing information, buyers often falsely claim to have received lower price offers from competitors, biasing salespeople's views of competitors' prices (Nagle et al., 2016).

The use of cost information is another important information-processing problem. One discussion centers on the use of marginal cost as preferred; however, many firms still employ full cost models (Lucas, 2003; Lucas and Rafferty, 2008). A particular problem here is determining the variability of capacity (Lucas, 2003), and as demand variability increases, full cost allocation becomes less precise because it does not reflect marginal cost (Hsu, 2011). Another discussion relates to the extent to which sales should have access to cost information. This literature discusses relations between cost information and learning from the market. Cardinaels et al. (2004) found that in informative markets (i.e. where competitors set prices correctly), market information can rule out effects of biased cost information. However, activity-based costing information is superior when market information is imprecise (Cardinaels et al., 2004). Bloomfield and Luft (2006) investigated how faulty cost data may lead to the winner's curse (i.e. that the winning seller loses profits through bidding too low) and how learning from the market can reduce this effect. Wilken et al. (2010) found that sellers with undifferentiated cost information set higher prices.

A different aspect of the information problem relates to how information is processed by the decision maker (Hallberg, 2017). Prospect theory and the literature on the use of intuition focus more on how individuals interpret information and suggest that intuitive processing $^{1}$ and rational processing of pricing information have different qualities (Artinger et al., 2015; Kahneman and Klein, 2009; Kruglanski and Gigerenzer, 2011). The need to make fast decisions makes it problematic for pricing managers to rely solely on rational processing because of the increased time used to collect and analyze data (Dane and Pratt, 2007; Dörfler and Ackermann, 2012). The use of heuristics to make decisions, however, is prone to bias. Artinger et al. (2015) therefore argued that in uncertain environments, complex decision algorithms potentially incur larger errors due to the inability to correct for noise in the data. On the other hand, "a simple heuristic instead incurs error in prediction owing to its bias but is much less sensitive to fluctuations in the environment, which can make it a robust and high-performing strategy” (Artinger et al., 2015, p. 47).

The information problem, then, involves three issues. First, market information is uncertain and difficult to obtain. Second, the use of cost data is problematic, as it may reduce the ability to learn from the market, and third, the use of both intuitive and rational processing 
of information is potentially important. The studies discussed here, however, mainly use experiments, modelling and surveys in their investigations - it is therefore unclear how market and cost information is used in decision-making processes in organizations, and how intuitive and rational processing of information interrelate in concrete organizational processes.

The coordination problem is based on the dispersed nature of pricing information. The pricing decision relies on information that is located in "different parts of the firm, who have different sets of information” (Dutta et al., 2003, p. 628). Information about cost and capacity may not be freely available in IT systems, such as Enterprise Resource Planning, across firms' organizational units. Likewise, demand and logistical information may be scattered around the organization. In principle, IT and pricing systems could handle these problems, but a fully automated pricing process may generate further issues, especially because information may be imprecise and inaccurate. To base pricing decisions on the relevant, available information in the organization, coordination of pricing decisions is necessary. Extant literature is not well developed in relation to the coordination problem.

The control problem arises because the different departments and entities in an organization are not necessarily aligned when it comes to the pricing decision. In particular, the performance of the sales functions is still often measured and incentivized based on revenues, not profit (Homburg et al., 2012). Further, customers exert pressure to increase discounts (Joseph, 2001; Lancioni, 2005; Stephenson et al., 1979), and sales may follow the “path of least resistance and grant higher discounts” (Wilken et al., 2010, p. 78). The sales force, however, typically has superior knowledge of customers, their willingness to pay, and the competition (Frenzen et al., 2010). On the other hand, pricing and general managers have superior internal information, such as information on strategy, capacity and cost. Balancing the use of the sales force's local knowledge and handling agency problems is therefore key in pricing (Homburg et al., 2012; Jensen and Meckling, 1995). Literature on the price delegation issue, though, is unclear on how actors in processes share pricing information and does not investigate organizational processes in depth. Table I summarises the three problems.

Table I. Key problems in price decision-making

\begin{tabular}{|c|c|c|c|}
\hline & Information problem & Coordination problem & Control problem \\
\hline Key challenge & $\begin{array}{l}\text { How to interpret equivocal } \\
\text { and ambiguous market and } \\
\text { cost information }\end{array}$ & $\begin{array}{l}\text { Making decisions based on } \\
\text { all available information in } \\
\text { the organization. Linking of } \\
\text { cost, capacity, (market) } \\
\text { value and strategic } \\
\text { information }\end{array}$ & $\begin{array}{l}\text { Using salespeople's } \\
\text { knowledge while ensuring } \\
\text { that decisions are consistent } \\
\text { with strategic objectives }\end{array}$ \\
\hline Elements & $\begin{array}{l}\text { Intuitive and rational } \\
\text { processing of information }\end{array}$ & Communication processes & $\begin{array}{l}\text { Local knowledge; } \\
\text { incentives; strategic } \\
\text { objectives }\end{array}$ \\
\hline Theoretical sources & $\begin{array}{l}\text { Prospect theory; cost and } \\
\text { behavioral accounting }\end{array}$ & $\begin{array}{l}\text { Capability-based view; } \\
\text { coordination theory }\end{array}$ & $\begin{array}{l}\text { Principal-agent problem } \\
\text { (agency theory) }\end{array}$ \\
\hline
\end{tabular}




\subsection{A practice-based approach to pricing}

Accounting research has shown a renewed interest in understanding accounting through a practice lens (Chua 2007; Baxter and Chua, 2008; Jørgensen and Messner, 2010). Such an approach engages with the messiness of accounting processes and studies the situated practices through which accounting emerge and generate effects (Skærbæk and Tryggestad, 2010; Chua, 2007). A practice based approach is interested in the "the fine details of how people use the resources available to them to accomplish intelligent actions, and how they give those actions sense and meaning” (Gherardi, 2012, p. 2).

The practice approach treats practices as the unit of analysis (Korica et al., 2017), but practice-based studies "do not investigate practices as abstract entities, but rather they praxeologize phenomena, turning the study of decision-making into the study of decisionmaking practices” (Nicolini and Monteiro, 2017, p. 18). A practice is defined as a “'bundle' of activities” (Schatzki, 2002, p. 71); in other words, it consists of various activities. Activities and practices generate links between micro interactions and more extensive organization wide structures through an attention to both the concrete doings and activities of actors but also on the enduring practices that structure a particular organizations decision making process.

Different traditions define practices differently (Nicolini and Monteiro, 2017). To develop a relatively grounded understanding of practices, we focus on the commonalities identified by Nicolini and Monteiro (2017) rather than the more specific theorization of practices by, for example, Jørgensen and Messner (2010) and Baxter and Chua (2008). In this paper, we take "orderly materially mediated doings and sayings ('practices') and their aggregations as central for the understanding of organizational and social phenomena” (Nicolini and Monteiro, 2017, p. 2). This approach focuses on the social character of processes and their enactment to solve problems. Practices, then, are "not personal qualities" but are shared among organizational participants. Practitioners are the carriers of practices; however, practices exist only virtually outside of praxis (Jarzabkowski et al., 2016), meaning that they become meaningful when studied in specific contexts.

The practice-based approach transcends merely defining practices (Nicolini and Monteiro, 2017). In a similar vein, Jarzabkowski et al. (2016) argued that researchers should consider three elements: the what, who and how of a practice. The "what" focus on defining the practices that are the object of study. The "who" emphasize the actors that perform practices. The "how" accentuates the organizational processes in which practices are performed.

This brief discussion leads to the following implications for the current study: it requires an investigation of the practices and the actors executing the practices as well as how the identified practices shape the pricing processes and impact sales pricing decisions. The approach distinguishes between the activities that actors carry out and the bundle of activities that constitutes a practice. 


\section{Method}

Because pricing practices have been studied only to a limited extent, we applied an exploratory case study approach (Stake, 1995). The research process is characterized by an abductive logic (Dubois and Gadde, 2002), meaning that the researchers, after an initial open non-theoretical data-collection process, constantly move between the data, analysis and theory from the literature iteratively and non-linearly. This approach helps us achieve the depth required not only to identify and define pricing practices of the case firms but also to understand how they are utilized, interlinked and given meaning in processes. Further, this approach enables us to zoom in and out on the practices studied (Gherardi, 2012; Nicolini, 2009, 2012). Here, zooming in refers to looking at the details of a practice in its specific, local situation; zooming out refers to taking a broader view of a practice (e.g. in its wider organizational or processual context). Switching between these two perspectives helps us discover new aspects of the phenomenon under investigation (Nicolini, 2009). Put differently, through "magnifying or blowing up the details of practice, [...] certain aspects are foregrounded, and others are temporarily sent to the background” (Nicolini, 2009, p. 1412).

\subsection{Cases and case selection}

The two cases - DAN Cargo and DAN Communication - were selected based on the following criteria. It was important that both case companies had competence in pricing and that they prioritize pricing activities in the business. We sought firms whose sales force did not have full pricing authority, or the freedom to set any price above marginal cost. Only $11 \%$ of the companies examined by Hansen et al. (2008) gave salespeople full pricing authority. We were interested in cases with no or limited pricing authority, as this represents the majority of firms, meaning we were not seeking extreme cases (28\% and $61 \%$ of the companies, respectively; Hansen et al., 2008). Regarding differences, we sought a service and a manufacturing company operating in diverse industries. To gain insight into the role of pricing systems, we chose one company using a complex revenue management system (RMS) and one using a self-built Microsoft Excel tool, as is often used in practice. Another important criterion was access to data. Accessing firms' pricing processes can be problematic but was vital for this research. The authors knew stakeholders in the two case companies from previous projects and conferences, and one of the researchers is employed by DAN Communication. These existing relationships and the top management's commitment allowed better access. Three potential cases were excluded due to difficulties in securing full access.

The first case company, DAN Cargo, is a freight forwarder connected to a large airline carrier. DAN Cargo is responsible for utilizing the carrier's freight capacity but is managed independently. The company performs sales-price-setting daily upon requests from customers. The complexity of setting prices based on demand information (high volatility) and capacity planning is high.

The second case company, DAN Communication, is a manufacturer of communication devices sold in B2B markets. The firm faces challenges in coordinating pricing decisions, and there is strong pressure for discounts from customers. The analysis on DAN Communication focuses on the practices for sales transactions, that is, sales prices and 
not market/list prices, due to the everyday character of the pricing decisions and the similarity to the pricing decision made by DAN Cargo.

\subsection{Data collection and analysis}

Multiple data-collection methods were employed, ensuring triangulation of the data (Silverman, 2012; Stake, 1995): 21 transcribed interviews, four pricing meetings, one shadowing of a pricing system user (Czarniawska, 2007; see Table II for overview of primary data), and 22 pricing documents of direct relevance were included in the analysis. We conducted semi-structured interviews with employees across different hierarchy levels and regions. In many of the interviews, the interviewees described and demonstrated how they use specific tools on their computers, shared recent examples of pricing decision-making, and presented e-mail conversations with customers and colleagues involved in the process. Additional subject-related interviews (not transcribed) on pricing were conducted at DAN Communication.

\section{Table II. Overview of primary data collection}

\begin{tabular}{|c|c|c|}
\hline Interview & Company & Function(s) \\
\hline 1 & DAN Cargo & $\begin{array}{l}\text { President \& CEO, } \\
\text { Director Network \& Revenue Manager, } \\
\text { Strategic Pricing Manager }\end{array}$ \\
\hline 2 & DAN Cargo & $\begin{array}{l}\text { President \& CEO, } \\
\text { Director Network \& Revenue Manager, }\end{array}$ \\
\hline 3 & DAN Cargo & Strategic Pricing Manager \\
\hline 4 & DAN Cargo & Route Analyst 1 \& 2 \\
\hline 5 & DAN Cargo & Regional Sales Manager \\
\hline 6 & DAN Cargo & Route Analyst $1 \& 2$ \\
\hline 7 & DAN Cargo & Route Analyst 1 \\
\hline 8 & DAN Communication & Head of Sales Operations \\
\hline 9 & DAN Communication & Sales Manager, Nordics \\
\hline 10 & DAN Communication & Head of Product Management \\
\hline 11 & DAN Communication & Senior Director of Sales, ANZ (Australia/New Zealand) \\
\hline 12 & DAN Communication & Sales Director, Western Europe \\
\hline 13 & DAN Communication & Sales Director, APAC (Asia-pacific) \\
\hline 14 & DAN Communication & Managing Director, Central Europe \\
\hline $15^{*}$ & DAN Communication & Sales Manager, DACH (Germany, Austria \& Switzerland) \\
\hline $16^{*}$ & DAN Communication & Sales Manager, Retail DACH \\
\hline 17 & DAN Communication & Vice President (For a Product Category) \\
\hline $18 *$ & DAN Communication & CFO \\
\hline
\end{tabular}




\begin{tabular}{|c|c|c|}
\hline Interview & Company & Function(s) \\
\hline $19 *$ & DAN Communication & $\begin{array}{l}\text { Vice President Sales \& Operations, Europe, Middle East, Africa, } \\
\text { Central \& Latin America }\end{array}$ \\
\hline $20 *$ & DAN Communication & Channel Support Specialist \\
\hline $21 *$ & DAN Communication & Channel Program Manager \\
\hline Meeting*** & Company & Function(s) \\
\hline $1^{* *}$ & DAN Cargo & $\begin{array}{l}\text { President \& CEO, Director Network \& Revenue Manager, } \\
\text { Strategic Pricing Manager, Route Analyst } 1 \text { \& 2, Sales Force }\end{array}$ \\
\hline $2 *$ & DAN Communication & Head of Business Development \\
\hline $3 *$ & DAN Communication & $\begin{array}{l}\text { CFO, Head of Channel \& Sales Management, IT Staff, Procurement } \\
\text { Manager }\end{array}$ \\
\hline $4 *$ & DAN Communication & $\begin{array}{l}\text { CFO, Head of Channel \& Sales Management, IT Staff, Procurement } \\
\text { Manager }\end{array}$ \\
\hline Shadowing & Company & Function(s) \\
\hline $1 * *$ & DAN Cargo & Route Analyst 1 \\
\hline
\end{tabular}

* Interviews and meetings were recorded and analyzed, but not transcribed and coded.

** Only notes were taken.

*** Meetings were held after the data were collected.

We participated in several meetings after the data were collected and analyzed to verify the analysis. In a meeting at DAN Cargo, the results were partly presented and verified, and new pricing issues of DAN Cargo were discussed. Here, all previous interview participants of the case firm, plus the entire sales force, were present. At DAN Communication, the results were shared with and presented to various stakeholders. The head of business development took our report to the CEO. A few months later, it was decided that a new pricing system was needed. Subsequently, the researcher employed by the firm attended two meetings where the purchase and implementation of a configure price quote system were being discussed to speed up the sales pricing approval processes, making them faster and more data driven.

We also observed practices and collected documents on site. At DAN Cargo, one researcher shadowed a pricing system user to clarify and better comprehend the findings from the first interviews. We deemed this necessary given the complexity of their RMS. Further, we received screenshots of the system to support our analysis of the interview data. At DAN Communication, we were given a copy of the pricing system and shown how they use it in the interview. We had access to all sales data thanks to the employment of one co-author. Thus, we could check the actual performance numbers of the salespeople interviewed to verify and better understand the information provided. We focused on documents that serve as guidelines, policies and descriptions of relevant processes. The secondary data helped us to compensate for the weaknesses of the primary data. 
The process of collecting and analyzing the data and consulting the pricing literature was iterative: we analyzed interviews, and then we returned to the case firms to conduct more interviews. Following authors such as Dutta et al. (2003) and Zbaracki and Bergen (2010), we treated pricing as a process. Therefore, in both cases, we first conducted explorative interviews to get an understanding of the overall pricing decision-making process. From the beginning, we emphasized praxeologizing our questions (Korica et al., 2017). The co-authors read, discussed and analyzed the initial interviews in various sessions. Actions and processes, rather than themes and structures, were identified and analyzed (Charmaz, 2010). The guide for the semi-structured interviews was revised continuously and developed further based on the preliminary data, findings and new literature. For example, it soon became apparent that the processing of pricing information was paramount, so we reviewed the literature on intuition and individual judgment, and then returned to the case firm to probe this subject further. Revisions to the guide were primarily based on the previous interviews and the literature we consulted throughout the research process.

The data analysis then proceeded in a more systematic, but still iterative mode (Miles and Huberman, 1994). To structure the data and grasp the specific and broader contexts, we first coded for the process steps, which we perceived as useful for zooming in and out of practices (praxis). After mapping the process, we identified the practices and their corresponding activities in the data (practices). Third, we coded for the actors involved (practitioners) and materials, mostly in the form of pricing systems. To gain further insights into the context and complexity (praxis), we also coded for issues and challenges encountered in the processes.

Coding was performed in NVivo and yielded a practice coding scheme. Early versions of the scheme were challenged and revised. This process was repeated several times until the coding scheme was sufficiently comprehensive and relevant to the subject. After the coding scheme was finalized, the interviews were again coded twofold in NVivo, meaning coded independently by two researchers. The results were compared, and each coded line of all the transcripts was reviewed. For all the interviews, the intercoder reliability ${ }^{2}$ was $87 \%$ (DAN Communication) and 80\% (DAN Cargo) in the last testing round, which was deemed sufficient. Disagreements were discussed and resolved in this process.

\subsection{Coding scheme: practices}

Based on the described methodological process, we identified and validated the practices and accompanying activities used in the sales price decision-making processes at the two case companies. The practice scheme (see Table III) that emerged includes four practices: information-processing, interaction with the system, communication, and control and accountability. 
Table III. Coding scheme-practices

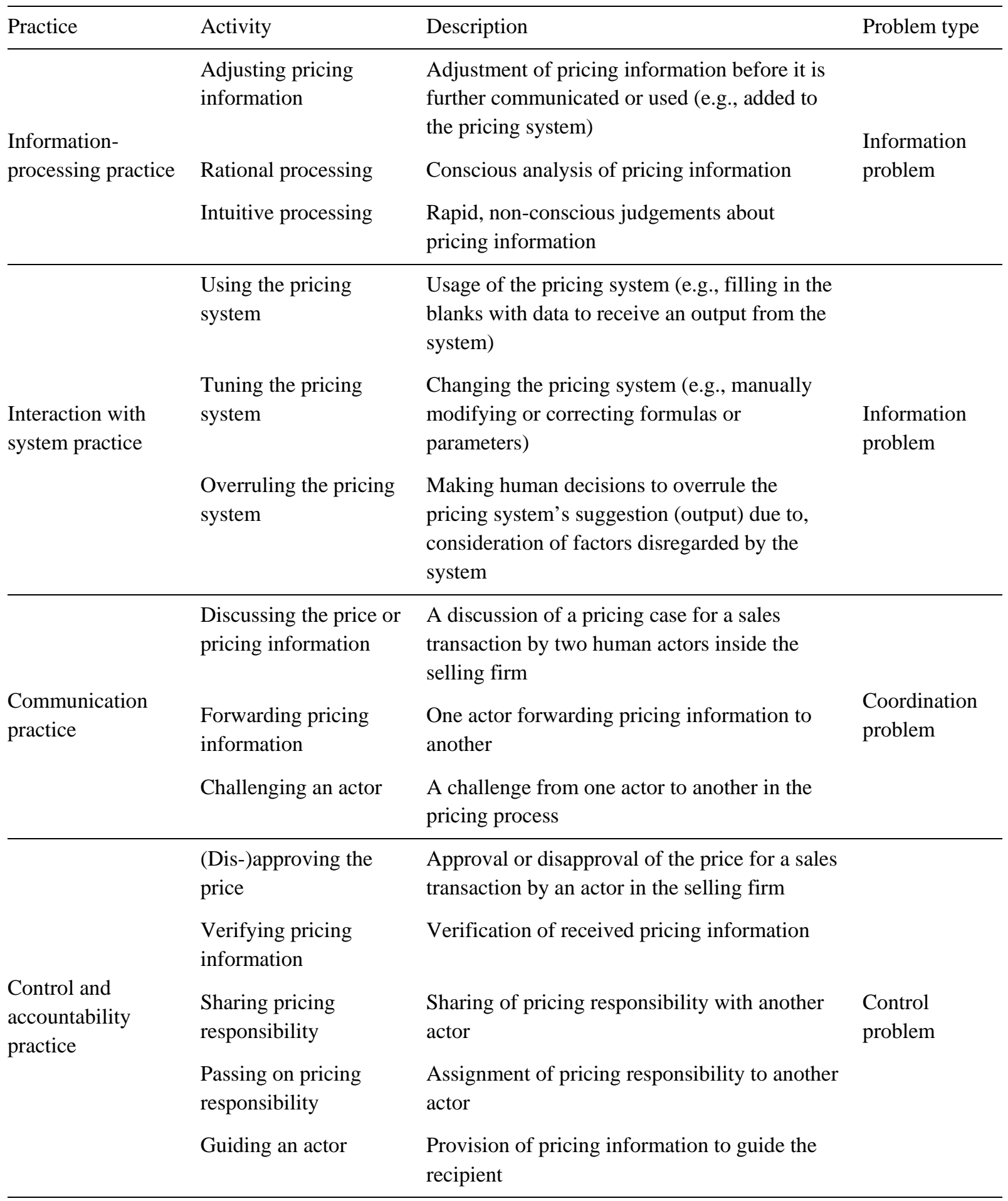

As argued earlier, the practice approach implies that practices are the unit of analysis, moving empirical research away from the individual (e.g. salespeople) as the primary focus (Geiger and Kelly, 2014). The scheme indicates the activities that compose a specific practice and the related problem. With regard to the three elements of practices, the scheme (Table III) in isolation answers the "what" at a rather general level, and the "who" and "how" to an even lesser extent. To gain more insight into this, we use the scheme in the subsequent case analysis, which explores in particular how practitioners are enacting the practices in praxis to 
address the three key problems of information, coordination and control (Jarzabkowski et al., 2016).

\section{DAN Cargo analysis}

\subsection{Introduction}

DAN Cargo is a leading air cargo carrier in Scandinavia. The airfreight market is influenced by various seasonal and geographic trends, many irregular conditions and high volatility. This fast-paced environment and the resulting variations in demand and capacity create high complexity in pricing decisions. A key challenge was the way that clients pressured the sales force. A route analyst explains:

There's a danger that you might put a price too low because you are good friends with the customer ... maybe select a wrong price because you know the customer or because you do not know the customer. The system helps you with this - it might, though, never take over $100 \%$ - but at least, it can help and guide you. You get a more helicopter view on the pricing because then it's not just emotions, but it is also facts that go into the price calculation. [Route analyst 1]

To reduce the negative effects of relational pressure and emotional decision-making, the company implemented a new RMS and centralized pricing decision-making authority. The system is built on algorithms, enabling fast rational processing of market information with the purpose of guiding the system users. In this process the system users are crucial because they evaluate the system's input and output and make the pricing decision.

The system defines a hurdle rate, which can be considered to be the price floor. The hurdle rate helps users decide which capacity should be sold to whom and when and at what price to achieve maximum profitability and revenue for a flight. If demand is high, prices will increase; if demand is low, prices decrease because the capacity for airfreight is fixed and relatively independent of demand. Considerable energy is devoted here to analyzing demand and capacity information. The RMS thus analyzes pricing information, coordinates decisions through collocating information and allocating capacity, and controls the sales force through the production of a minimum price.

Based on the empirical analysis, we designed a process flow chart to illustrate the pricing process for a specific sales transaction. The structure is based on the interactions of the various actors, and also systems, in the pricing process. The figure illustrates the process steps that the company follows to address the information problem (evaluating demand), coordination (allocation of capacity) and control (reducing price discounting based on relational pressure). 




Figure 1. DAN Cargo pricing process for sales transactions.

\subsection{Customer-Sales Representative (Step 1)}

Under DAN Cargo's more centralized decision-making paradigm, direct negotiations were minimized, and the sales representative (SR) was more caretaker than price setter. The new roles require holding customer meetings and gathering customer information, for two purposes. First, an increased focus on service should mitigate the potential negative effects on sales revenues from the lack of negotiation opportunities. Second, market information should be gathered to serve as input for the RMS:

For example, [in] Copenhagen, fur auctions have sold a lot of fur. Then we hear, "The auction went well, so there will probably be much fur cargo 14 days from now." It is those feelings you get, when you are out and talk to the customer. [Regional sales manager]

This quotation shows that the company creates an understanding of what is happening in the market by collecting relevant information from customers. The regional sales manager identifies input as specific occurrences in the market which could increase or decrease market demand for airfreight. The data gathered by the sales force are mostly qualitative and therefore support non-quantified expectations.

\subsection{Sales Representative-Route Analyst (Step 2)}

In the first process step, the information provided by customers and observations made in the market serve as the starting point for the pricing decision. The information is next forwarded to the route analysts at headquarters, who are using the RMS (henceforth called system users). System users are central in the pricing process because of their placement between the sales force and the system.

The information from the sales force is forwarded to and discussed in weekly meetings, dialogues, and discussions by the system users: 
It is typically our salespeople that have their fingers on the pulse. And in addition, we have organized meetings, so we have weekly sales meetings with all our regions. .... We have lost this one customer, or we have found a potential new customer that increases demand. Or now, we believe that Lufthansa will cancel three days next week, so that means there will be some extra demand. Or now, Norwegian will come in and start flying somewhere in the United States. ... What should we do about it?...Well, there are many different types of information.” [Strategic pricing manager]

The company's planning and forecasting are heavily dependent on receiving input from the sales force because they have a major role in forwarding information and guiding the system users. The system users informally discuss pricing information with the sales force every day to ensure that they are always well informed and up to date.

The system users must be cautious about demand input because salespeople compete for capacity on flights and exaggerate demand. The system users are aware of this conflict of interest and often adjust information to remove potential biases. System users use various sources of information, and when these sources with different interests make similar statements, the information is considered to be verified and more believable. A second approach to processing information is through experience-based intuition:

When there are at least two or three [people] that begin to mention the same thing to me, that's when my stomach starts to say: "Then, we have to do something. ... Now there is a lot, or now there is a little, right?” Then I can tune it that way. ... So, if they say to me, "I have to rely on something down from Germany, and it is average pallets with 2 tons" - then, no. My gut tells me - and now I have been sitting on this for many years - that it's not 2 tons. This is a volume of only 1,650 kilos, so I assume that it's only $1,650 \mathrm{~kg}$. [Route analyst 1]

Such qualitative data need to be converted into a quantity that can be entered into the system. Today, no algorithm or similar tool can perform this task. Instead, the system users rely on the information received, listen to their gut feelings to understand what the effect will be, and then act accordingly (Step 3). Therefore, the system users process intuitively to transform the input from the sales force into a quantifiable value in an algorithmic parameter of the RMS.

In summary, the practices of information-processing and communication are key in this step of the pricing decision-making process. The system users carefully consider the information forwarded by the sales force because of the potential for biased information. Thus, DAN Cargo's information-processing practice is characterized by the activities of verifying and adjusting information. In doing this, the system users rationally and intuitively process the received inputs before entering them into the system. The practice of communication is vital in this step given the necessity of forwarding and discussing information. 


\subsection{Route Analyst-System (Step 3)}

The system forecasts and deploys the available capacity, which is matched with the anticipated demand by the system's optimization algorithm. The different inputs are combined to determine the hurdle rate. The automated forecast must be changed manually if the system's demand forecast contradicts the organization's expectations. The automation of the pricing decision through the RMS makes verifying pricing information even more important:

It [RMS] can calculate a lot and can anticipate a lot based on some statistics and things like that. But the manual input may become even more important in the future, the more you leave [for] the system to calculate. [Regional sales manager]

The system can calculate the hurdle rate through its algorithms, but a human actor must tune it manually.

So you can tune ... . If you know that demand will go up ... let's say there is a factory. They need [to send] something to a factory in the United States. Then you can go to our RMS and tune on demand on the OD - origin destination - where it flies off and on. ... And that helps to tune up the price because we expect there to be more. [Route analyst 1]

In many instances, it is not sufficient to simply use the system; instead, system users must actively tune the parameters of the RMS (e.g. turn up the demand). The system's algorithm is then reconstructed to produce the hurdle rates in relation to new demand information.

The system also has problems with non-recurrent incidents. They are not removed automatically, resulting in a bias which must be eliminated by tuning the system:

Historical data need help, and sometimes, a market may change, which makes history obsolete. And then, you have to adjust for that, and then, you can tell the system what you think is happening. We could not forecast the ash cloud [which grounded airplanes for six days in 2010], but the system has historical data, and we need to remove that. [Route analyst 2]

The system does not always produce valid forecasts, which affects its suggested prices because of its rational processing. The system also does not automatically reject historical information of irregular variances, and system users therefore must tune the parameters when interacting with the system.

In sum, after processing the information (Step 2), the system users start the practice of interacting with the RMS. The system is often tuned while being used by the system users, for example by correcting the algorithms for producing forecasts when historical data are an invalid basis for predicting the future.

\subsection{System-Route Analyst (Step 4)}

The produced system output is evaluated and sometimes corrected. The system's capability to make or to support adequate decisions is dependent on being operated by the system users: 
Either you are someone who expects the system to take all the decisions for you. And if that's what your expectation is, then the system expects that you tune it optimally. Or are you one of those who use a bit of what the system spits out and then use a little of your gut feeling and then say: "We must try this, and then we will see what result we get out of it.” And then we can then afterwards use it in, perhaps, tune it up after the experience we have made, right? [Route analyst 2]

You must know how your system works, and you should know what it is your system can not do for you. Where are the weaknesses in the system? And this is what I should know to be better able to help. If you do not understand how the system works, then it becomes too hard because then you do not trust the system. The system must be the work of average things running through, and then there are all the exceptions. [Route analyst 1]

This quotation shows that the system guides the system users but also highlights that the system is reliant on both manual input and evaluation of the output. The system produces accurate forecasts in some areas. However, its price calculations sometimes do not account for the specificity of particular transactions:

If we are to fly a car, a car weighs maybe not very much, but it is mega hassle to get in and out of an airplane, right? So it should not just be priced with a per-kilo rate. ... If for example this is a red Ferrari, then one cannot just put Danfoss pumps on top of it, right? [Regional sales manager]

The price and cost output of the RMS are corrected to reflect the specific transaction. The system outputs are analyzed to consider the particularities of specific transactions. The system's output is thus overruled to meet the requirements of the specific freight, if necessary:

I trust the system when it has got the right inputs, and the inputs have to come from me, among others. [Regional sales manager]

The system cannot automatically make accurate decisions in all instances. The system users' gatekeeper function is to overrule the system based on rational and intuitive processing of the system's information outputs (practice of information-processing) when doing so is deemed necessary. The practice of interacting with the system (using, tuning, and overruling the system) eventually determines the pricing output.

\subsection{Route Analyst-Sales Representative and Sales Representative-Customer (Steps 5 and} 6)

So far, the dialogue between the system users and the sales force has been on customer information (Step 2). Now, the process reverses. After approving the system output (the minimum price), the system users forward it to the sales force: 
We start with a negotiating point and a desired rate ... and then, they [the customer] say "yes", or they say "no". And then the question is what it is the customer is willing to pay. [Regional sales manager]

Before the sales force can begin negotiating with the customer, the price is internally forwarded to and discussed with the sales force. The input, which primarily is a transformation of the initial information at the beginning of the flowchart, has gone from unspecific talk to a specific minimum price. This guidance delineates the safe area in which the SR is allowed to play, or alternatively, the transaction is disapproved, and no sale is completed, for example due to a lack of capacity.

\subsection{Conclusion of DAN Cargo analysis}

In conclusion, transaction pricing at DAN Cargo is centrally organized and led. The sales force cannot propose a price in negotiations before they receive authorization from the system users. Thus, pricing responsibility is ultimately passed on to the system users, who seek to coordinate capacity between geographies and salespeople and to control the sales force's pricing behavior. The main task of the sales force is to estimate demand. Their forwarded or adjusted input, however, is not inserted directly into the RMS. Instead, the input is first verified, for example by comparing it with information from other markets, or is intuitively processed and then adjusted. System users tune the system and work with the algorithms to produce more realistic forecasts and, thereby, make better pricing decisions. They overrule the system's outputs when these seem out of tune with demand or if specific transactions warrant it. The system itself cannot guarantee the accuracy of decisions made. Instead, the RMS becomes a purposeful part of the pricing process only once human actors tune the system. The system output further triggers the actors' practices, such as overriding the system. Generally, at DAN Cargo, the main practice of interacting with the system is highly dependent on the practices of communication and information-processing and their related activities. Once these practices are enacted, the system's rational processing of information can produce prices that are, in the eyes of the firm, optimized.

\section{DAN Communication analysis}

\subsection{Introduction}

The second case company, DAN Communication, is a global manufacturer of hearing and communication devices. A few years ago, the firm started a new business division with consumer products that today accounts for 35 percent of its total revenue. The products are specifically developed for the mass market and sold primarily through consumer electronics and specialty distributors and stores. The interviewed staff members have responsibilities within this division only. The focus of this analysis is on the sales prices for its B2B customers. 


\subsection{Customer-Sales Representative (Step 1) and Definition of Process}

In most of the transaction deals, SRs transact by selling at or higher than the internally defined minimum price. Thus, they can "reach the decision within the same meeting" (sales manager, Nordics). However, in many cases, the sales price process becomes more complex as a result of a need for coordination and control. Typically, this happens when a customer requests a price lower than the minimum price or has specific requirements for discounts or marketing support that often greatly affect profitability. Generally, one "should never expect them [customer] to do anything else than pressure us" (head of product management), and the profitability and margin targets of the deal is often at stake. A sales manager (SM, including sales managers and sales directors) argues:

Customers always just want money off, money off, money off. ... So, in a way, by them [SRs] not having the ability to do that, it means that they don't get in a difficult situation where they feel that maybe they've got to offer it. Because they can't. They have to say, "I will go back and ask the business." [Senior director of sales, ANZ]

The customer exerts relational pressure. The quote implies that salespeople might be tempted to close the deal in certain situations, such as when sales are needed at the end of the quarter.

Here, customers use their close relationships with SRs to push for price reductions:

If they go way back, and they've done each other favors in the past, so you remember, "I did this for you." "Yeah, I remember that." "So now you do this for me.” That's for sure a part of the game. [Head of sales operations]

Past favors in the relationship enable customers to challenge the SRs. Salespeople are hired because of their industry networks, and over time they become further embedded in relationships with customers. Over the long term, however, these relationships might not always benefit the selling firm. Sales discounting behavior is therefore subject to control.

The chain of command for sales price approvals involves various actors at the local and central levels. There is often only a thin line between discussing a price and passing on responsibility, because DAN Communication has no clear rules for when and how employees must ask for approval. This broadly defined governance allows flexibility and serves three purposes: 1) assembling information from different parts of the organization, 2) making coordinated decisions, and 3) controlling the discounts given by SRs. Figure 2 maps the approval process. 


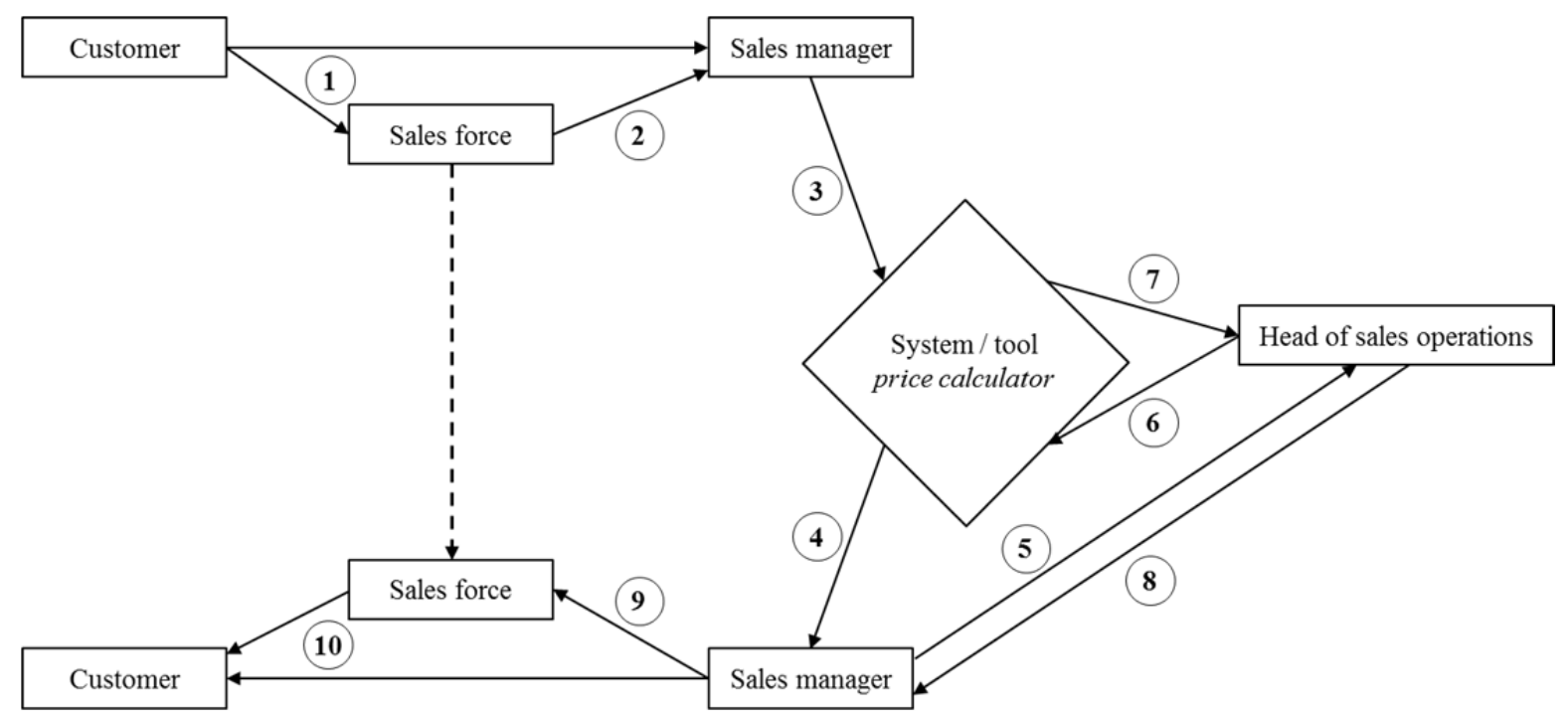

Figure 2. Price approval process at DAN Communication.

In routine, simple cases (about 70\%), approval is not needed and the SR immediately sets the price in the negotiations. This situation is represented by the dotted line and is not the focus of our analysis. In the other cases, with potentially big impacts on profits and margins, other actors are involved, as the figure illustrates. These are our focus.

\subsection{Sales Representative-Sales Manager (Step 2)}

The SR involves the SM when in doubt about the price decision:

If the colleague is a bit more experienced, then they usually know roughly what they have to play around with in terms of discounts or marketing support. But if it's a new case for them or if it's a fairly new employee, then they usually turn to their manager. [Sales manager, Nordics]

The SM gets involved in the customer interaction and determines whether the customer is eligible for a special price, for example due to a larger order volume. Experience tells SMs whether they can "feel comfortable that the customer can actually handle that extra volume" (sales manager, Nordics). Knowing which customers can and which cannot is a matter that the SMs "basically just learn over time” (sales manager, Nordics). SMs, therefore, use experience-based intuition to gauge the effects of discounts. However, the sales decisions are often analytically driven, as stressed by a SM:

There's nothing there that's just available to offer. ... Every dollar and every cent counts, so it has to be justified. [Senior director of sales, ANZ]

The firm seems to expect a rational decision - in other words, a profitable deal based on margin requirements. The SRs, however, are deliberately not given the relevant tools and cost information to evaluate whether a certain price less than the minimum price is still a good price from a marginal point of view (Step 3). ${ }^{3}$ Thus, the SRs cannot use the potential contribution margin (CM) of the transaction as a justification. 
In summary, the SRs have the role of forwarding relevant information to their SMs. It is not fully defined what information is necessary and what justifications are acceptable, but through experience the SRs get a better understanding of what they need to provide to their superiors.

\subsection{Sales Manager-System and System-Sales Manager (Steps 3 and 4)}

Based on the received information, the SMs begin to interact with the price calculator. ${ }^{4}$ If the calculated CM is higher than a certain percentage, the number turns green to indicate a healthy or good margin. When the CM percentage is too low, the number turns red, suggesting disapproval of the deal. After using the system, the SMs evaluate what further actions to take.

The system has limitations and might offer misleading suggestions. According to a $\mathrm{SM}$, the system is faulty because green does not always indicate a good deal, and red does not always mean that a deal should not be approved:

There might be products which are old where, if you use a price calculator, and you wait until the price gets green, the price will still be so high that the customer will not buy the product. So, for example, product [name withheld]. That's a very expensive product for us, and it's an old product, so we cannot sell this product anymore, in most cases, with a healthy margin. So, based on the price calculator, we should always say "no" to the customer [while in reality it is still sold]. [Sales director, Western Europe]

The calculator exists to rationally process information for the business's success, but when using the system, the output is often reasonable only at first sight. The system's output guides the system users, although the SMs also challenge the system by drawing on other types of information, such as the product's lifecycle stage. The system users coordinate different decisions by considering various types of information and strategies not available on the local level.

Many SMs believe that they perform a guardian role in using the system. The SMs deliberately do not give the SRs access to the tool:

They think, “Oh, green must be good, so I can sell at 30\%,” which I think should not be the case. I think we have to be strict about it. [Sales director, Western Europe]

From the SMs' perspective, the SRs probably rely too much on the system and do not know how to correctly interpret its output. The SRs might also be inclined to sell at the lowest margin possible to take the path of least customer resistance (Frenzen et al., 2010). In other words, the SMs think the SRs should be controlled.

The price calculator is an important tool for the SMs because it rationally calculates the CM, which is a key criterion for approval of decisions, although it is certainly not the only parameter considered by many managers. The SMs are the only local users of the price calculator and therefore possess knowledge that the SRs might not have, such as insight into the CM or the system's limitations. A grey or dangerous area is a matter that is perceived 
differently by every SM. Depending on such interpretations, the SMs may decide to involve the head of sales operations (HSO) at the headquarters level.

When it is believed that the calculated CM is red or in a grey area, the SMs have to be very confident that approving or disapproving the price still falls within their responsibility. The SMs have the flexibility to decide when to pass on the pricing responsibility, as it is not "overly clearly defined when I can make a decision and when not” (sales director, Western Europe). If the SMs are uncertain, they can send the information to the HSO. The system output, thus, guides the SMs and determines the next activity and practice, such as passing on responsibility and forwarding information to the HSO.

\subsection{Sales Manager-Head of Sales Operations (Step 5)}

The centrally located HSO is the next person in the chain of command and has final decisionmaking authority:

I also have a pretty good understanding of roughly what we can do, but then, I usually like to have it double-checked by the HSO. [Sales manager, Nordics]

The lack of clarity in the governance mechanism leads to a feeling of insecurity, increasing the complexity of the pricing process. By reaching out to the HSO "just in case" (sales director, Western Europe), the SMs stay “on the safe side” (sales manager, Nordics) because, in this way, the "four-eye principle" (managing director, Central Europe) is maintained; in other words, the pricing responsibility is shared or even fully passed on to the HSO.

Although the SMs potentially have more insights than the SRs at this stage, the SMs also encounter problems with information asymmetry:

It's very difficult for us in sales to have a good overview and understanding of what HSO is sitting on in terms of production and sales forecast. [Sales manager, Nordics]

In his eyes, the HSO has other sources of information (e.g. global overview of inventory, global demand) which can aid in making a coordinated decision.

When the SMs reach out to the HSO, they often give their opinion of why they approve of the deal or what about it concerns them because, ultimately, the SMs need to justify why they are asking for a special price. Briefly put, the SMs describe the case in an email, often with the price calculator and the current numbers attached to it.

If he doesn't know the customer, I may briefly describe the customer. Also highlighting, if it's a customer that I clearly feel very confident with. [Sales manager, Nordics]

This quotation shows that intangible factors, such as expressions of opinions and feelings, are highly important, so such information needs to be forwarded.

The HSO draws together diverse sets of information and coordinates decisions. Also, the information must be adjusted because the HSO might be unfamiliar with the local environment, such as customer type. Involving the HSO activates the next person in the chain of command, which implies a shift in the delegation of authority to approve decisions. 
5.6 Head of Sales Operations—System and System-Head of Sales Operations (Steps 6 and 7)

With the information from the SMs, the HSO can evaluate the numbers and "do the math contribution-wise” (HSO). Like the SMs (see steps 3 and 4), the HSO considers more factors than just the CM. The HSO explains that his practice of interacting with the system has changed because of the experience he has gained:

In the beginning, if the number turned red, if the figure turned red in my Excel spreadsheet, I immediately said, “No”. But today, I look at the number, and I say, "Okay, fine, so is this an end-of-life product? Yes? No? Do we have tons of inventory that we essentially need to get rid of? Yes? No?... Will we shortly introduce a new packaging, so essentially we would like to deplete this inventory in order for us to introduce the new packaging as soon as possible?” Then, I'm also more motivated to say, "Yes". [Head of sales operations]

The HSO makes judgements primarily based on the global profit-and-loss statement and the need to meet the global CM targets, but he also looks for potential reasons to dismiss the output and overrule it. Overriding the system can also mean that a transaction shown as green in the tool is disapproved. The arguments against the system's recommendation cannot be found in the price calculator but become visible when the human actor considers "a number of circumstances around the product” (HSO). The HSO further elaborates:

That's the beautiful thing about a human brain. You can juggle these 15 different kinds of small and big pieces of information that are all part of the whole picture, right? You can juggle those in a couple of seconds, and all these things you cannot put into a pricing calculator, even though we would love to do that. [Head of sales operations]

The HSO uses the tool but may overrule its suggestion when he believes that other factors should be weighted higher than the price calculator. These factors serve as a sort of "mental check" (sales director, Western Europe) that does not exist in writing. This mental check consists mainly of domain-specific and experience-based intuition, developed over time in combination with rational processing of information.

Whereas the human actor develops higher intuition with greater experience and learning, the system does not get smarter over time unless it is tuned by a human (see Section 4, “DAN Cargo analysis”). However, DAN Communication maintains and updates but does not change its tool. The HSO argues:

I think the benefit is that it [the process] has a human touch to it. I think the benefit is that we have a conversation about many of the cases, and during those conversations, everything that cannot be weighted and put into an Excel spreadsheet and turned into something that is plus-minus, XYZ, that comes out. And I think that's a value in the process or in the structure. [Head of sales operations] 
The practice of communicating between different actors is necessary for the HSO to make the decision. As a result, he decides to continuously question and, consequently, in specific instances, to override the system and to discuss pricing with the SMs.

In sum, the HSO communicates extensively with other parts of the organization and uses both rational and intuitive processing to gauge system output and to (dis-)approve prices. When outputs are interpreted to be invalid, the system is overruled.

\subsection{Head of Sales Operations-Sales Manager (Step 8)}

From this step onward, the flow is reversed toward local sales and customers. Triggered by the system's proposal and the evaluation of the system output, along with various other business factors, the HSO decides what and how to tell the SMs. Often, he provides not only the decision but also further information:

I will tell him, so I will be very open about that: "You can do this, but you should know that this is going to pull down your overall contribution from your business. Hence, you need to find some other business that pulls it up again in order for you to hit your contribution margin target.” [Head of sales operations]

As illustrated in this quotation, the HSO forwards supplementary information to the SM. With this warning, the HSO not only challenges but also guides the SMs. A SM further adds:

I think that the HSO is also doing a great job in that, challenging us in sales and asking us about the dynamics and what we should sort of take into consideration ... And then usually, the end result is that I am given a sort of a small price range that he tells me: “Okay, ideally, this is the price you should go for. However, if it's really tricky and tough competition, this is the absolute minimum price.” ... And then I do my best to land somewhere in between. [Sales manager, Nordics]

The HSO forwards relevant information, which the SMs then take into consideration. This also serves a safeguarding purpose for the HSO, which again relates to the practice of control and accountability. By reaching an agreement together, the actors (are perceived to) share pricing responsibility.

\subsection{Sales Manager-Sales Representative and Sales Representative-Customer (Steps 9 and} 10)

The newly given price or price range is now the safe playground for the SMs. They feel more comfortable because the involvement of the HSO has reduced their personal risks and responsibility. Now, the SMs pass the information on to the SRs:

The customer wanted $\$ 12$, but I would tell my SR a higher price to try to get him to close it higher first. I will tell them: "Try and sell it at \$13 first.” And then, if they come back and say, also give me some reasons ... Then, I know, okay, we have tried our best, and then I will let it go at the lower price. [Sales director, APAC] 
In this step, depending on the SMs' previous performance and experience with the SRs and customer (Sales director, Western Europe), the SMs often challenge the SRs to push the customer a bit harder - making one last attempt to raise the price above what the customer sought.

In conjunction with the previous step, the reversion of the process to the customer is intended to stimulate and control the next actor in line to reduce discounts. The information provided to the HSO is adjusted for this purpose. Thus, the SMs are also gatekeepers in this step, even as they also have a guiding role.

\subsection{Conclusion of DAN Communication Analysis}

Overall, the case analysis shows how DAN Communication addresses the challenge of meeting customers' price expectations while controlling discounting. To alleviate the pressure of salespeople and managers' uncertainty in the process, employees follow a chain of command. When a customer requests a price lower than the perceived minimum, the pricing decision is controlled and coordinated across the hierarchy, especially because important information is not accessible at the lower levels. SRs do not have access to cost information and therefore cannot judge profitability of specific deals. Because of this, an approval process is started that is rather informal. It is further characterized by tacit knowledge rather than clearly defined rules in relation to the practice of control and accountability.

\section{Discussion}

\subsection{Case findings}

This section presents the findings of the cases (see Table IV) and relates these to the literature to highlight the study's contributions. The pricing process in both firms was an interactive chain of practices across the organization. The analyzed pricing practices are durable activities which organizational actors share and use to resolve the information, coordination and control problems. In the cases studied, price-setting for a specific sales transaction is therefore not always a single decision made by one individual; it is also a collective effort achieved through a bundle of activities, belonging to certain practices that together lead to the pricing decision. 
Table IV. Practices of case companies

\begin{tabular}{|c|c|c|}
\hline & DAN Cargo & DAN Communication \\
\hline $\begin{array}{l}\text { Key problems in pricing } \\
\text { processes }\end{array}$ & $\begin{array}{l}\text { - Information problem: Uncertainty } \\
\text { about information and complexity } \\
\text { in information sources between } \\
\text { local units and headquarters } \\
\text { - Control and coordination problem: } \\
\text { Reducing relational pressure and } \\
\text { transferring demand information to } \\
\text { central pricing so that prices can be } \\
\text { coordinated }\end{array}$ & $\begin{array}{l}\text { - Control problem: Ensuring that } \\
\text { relational pressure does not lead to } \\
\text { margin leakage } \\
\text { - Coordination problem: } \\
\text { coordination of inventory, product } \\
\text { introductions and across markets } \\
\text { - Information problem: Sales are not } \\
\text { distracted by cost and capacity } \\
\text { information. This information is } \\
\text { evaluated in the accountability } \\
\text { process }\end{array}$ \\
\hline Key practices & Interaction with system & Control and accountability \\
\hline $\begin{array}{l}\text { Practices supporting } \\
\text { primary practice }\end{array}$ & $\begin{array}{l}\text { - Communication } \\
\text { - Information-processing }\end{array}$ & $\begin{array}{l}\text { - Information-processing } \\
\text { - Communication }\end{array}$ \\
\hline $\begin{array}{l}\text { Key interaction between } \\
\text { practices }\end{array}$ & $\begin{array}{l}\text { Practice of interacting with the } \\
\text { system (tuning and overruling), } \\
\text { dependent on the practices of } \\
\text { information-processing (adjusting, } \\
\text { and intuition) and communication } \\
\text { (forwarding and guiding) and } \\
\text { accountability and control practices } \\
\text { (verifying information) }\end{array}$ & $\begin{array}{l}\text { Practice of accountability and control } \\
\text { is linked to the practices of } \\
\text { information-processing (adjusting, } \\
\text { rationality, and intuition) and } \\
\text { communicating (discussing, } \\
\text { forwarding and challenging) }\end{array}$ \\
\hline
\end{tabular}

In the pricing processes studied, "practices exist in configurations” (Nicolini and Monteiro, 2017, p. 4), as also argued by other practice researchers such as Jarzabkowski et al. (2016) and Gherardi (2012). This means that a practice cannot be found in isolation, as it is bound and related to other practices. At DAN Cargo, the key practice of interacting with the system was interrelated with communication and information-processing practices information is collected, communicated, verified and fed to the system, and the system output is analyzed and corrected. At DAN Communication, the main activities related to the practice of control and accountability was informal and occurred in relation to practices of communication and information-processing.

The context in the pricing process is rather dynamic, indicating that practitioners who enact a practice need to adapt to new situations and that practices are "neither mindless repetition nor complete invention" (Nicolini and Monteiro, 2017, p. 6). Additionally, this paper supports the argument of Jarzabkowski et al. (2016) that, in practice-based research, it is key to focus on the "interaction of the what, who, and how of practices" (p. 250). Investigating these three elements in isolation, or only listing the practices, would have not yielded the same results.

This finding extends the market view. The market-based literature analyzes pricing practices generally, focusing on the information used (Ingenbleek et al., 2003; Ingenbleek and van der Lans, 2013). The practices developed here are finer-grained ${ }^{5}$ than the three pricesetting practices which use cost, competitor, and value information (Ingenbleek and van der 
Lans, 2013). We also illustrate how various types of qualitative and quantitative information (e.g. capacity, cost or value) are used by interlinked practices. Furthermore, information is not trusted per se. Multiple actors verify and check information, adjust it, process it via calculations or RMS and finally overrule calculations and systems output. Information is thus an uncertain resource that is processed and controlled through multiple interlinked practices.

The study also extends behavioral market research that focuses on determining whether intuition or rational processing is optimal in pricing. The pricing process is a series of interconnected practices in which intuitive and rational information-processing are dependent on and interlinked with other practices. Intuitive and rational processing, thus, are not performed by isolated individuals but are embedded in practices that affect and feed judgements. For example, the ability of a RMS to rationally predict demand and set prices is potentially flawed. The practice of communication and the activities related to the practice of interacting with the system, such as tuning the system and overriding its output, are found to be necessary in the case of DAN Cargo. Furthermore, we document situations in which intuitive feelings determine subsequent practices and activities, for example when the system users experience doubt and decide to verify information or when the SMs at DAN Communication have an instinct that tells them not to approve the price but to pass the responsibility to the HSO. In this way, individuals' usage of rationality and intuition is spun into a web of social practices. The effects of rational and intuitive information-processing should be judged not solely from a cognitive perspective but also in their social context and through their interconnections with other practices.

This case study's findings also extend the accounting and control research on pricing delegation, which is mostly experimental and normative. Our analysis of processes occurs in a context in which the core issue of pricing delegation is present: on one hand, individual sellers have direct access to market information but might be tempted to offer customers toolow prices in response to relational pressure and reward structures. On the other hand, the central staff has insights into capacity and cost information, which justifies centralization. The central levels in the firms deliberately do not share cost and capacity information, as discussed in Bloomfield and Luft (2006) and Wilken et al. (2010). We extend their research by illustrating how information and accountability are shared and where sellers are tested on their requests for discounts for their customers and their input regarding demand. Our findings indicate that studying the pricing process in terms of choice of a structure and access to cost and market information alone is too narrow - pricing practices verify information, share accountability and coordinate throughout the process. Sales price decision-making is thus not just a structure or a singular decision but a process involving multiple activities and practices that enable actors to progress despite uncertainty and problems with information, coordination and control. In other words, we extend the pricing delegation literature by shedding light on the practices and corresponding activities that make a given level of formal centralization of the pricing decision-making work.

\subsection{Managerial implications}

The study results have two main managerial implications. First, developing insights into firms’ pricing practices is key for managers seeking to understand their own pricing 
processes. The rich description and critical reflection on practices can empower practitioners (Gherardi, 2012). As advocated by Nicolini and Monteiro (2017), the best practice that researchers can follow to help "practitioners refine their practice is to offer them rich examples they can use” (p. 16), as this, for example, may establish new possibilities for abductive learning. In line with Eikeland and Nicolini (2011), we believe that the practices of the two cases support managers in questioning their own conventional practices and thinking about new ways of doing and saying. For instance, many companies aim to set up new governance mechanisms and approval levels to address price erosion, customer relational pressure, margin leakage, and price discount behavior. Considering such issues from a practice-based view can give managers further insights and inspiration for establishing, engineering and developing such pricing structures.

Second, this research shows how the ability to address complexity is related to the multiple practices used to make pricing decisions. These practices are social and shared among groups of organizational members. Reconfiguring the pricing process, therefore, is difficult because of the multiple elements and practices to be changed. This analysis points to a number of important questions for analyzing and changing pricing processes: Which communication patterns are especially important for coordinating pricing information? To what extent are employees' experience and intuition important for pricing decisions? What are the limitations of the rational pricing system, and how can they be overcome? How should pricing authority be delegated, and are informal practices important for making the pricing process work? How can existing practices be used in a new process or structure to reduce potential resistance?

\subsection{Limitations and future research}

The current study has a number of limitations that future research could address. First, it uses a relatively bottom-up empirical research approach to the two case firms. Other researchers from the pricing domain may wish to test the relevance of these practices in larger, quantitative studies.

Second, this study focuses on how actors within the firm share and adjust information for making pricing decisions, assuming that the information is already located inside the firm. Future research could begin one step earlier and address the practices that companies and, in particular, salespeople use to gather pricing information from the external environment (e.g. customers, competition, markets). Doing so would make the research approach potentially more network-based.

Third, we have focused on complex decisions and the parts of the pricing process where pricing was problematic, leaving simple, routine decisions unstudied. Thus, our findings are not relevant for routine decisions. However, the types of decisions studied in extant research (e.g. Bloomfield and Luft, 2006; Van den Abbeele et al., 2009) are hardly simple or routine given the complexity of the decisions they study. Furthermore, the decisions studied in the market literature are also not simple or routine, as this literature directly problematizes the use of cost, competitor and value information. 


\section{Conclusion}

This paper has sought to understand how firms set prices focusing on the practices and social interactions that lead to the price decision. This approach departs from extant research. The market perspective seeks to understand how customers' willingness to pay is evaluated through an individual's processing of customer information. The accounting view focuses on the determination of optimal levels of decentralization and how access to different kinds of cost information affects pricing decisions. These perspectives do not devote sufficient attention to organizational practices and how firms organize for pricing in practice.

The practice lens is an interesting approach to study pricing as it allows for a finergrained understanding of the practices and processes that lead to a price decision. Such research may help answering critical questions for research and practice, such as what is practitioners doing when they set prices? How is information collocated? How are pricing systems output evaluated? How are decisions coordinated and controlled in organizational processes?

In order to make a price decision the selling firm has to deal with three problems concerning information, control, and coordination. These problems are managed by enacting four practices - information-processing, communication, interaction with pricing system, and control and accountability. These practices are composed of activities that are interlinked in processes. At DAN Cargo, for example, evaluating customer information used the activities of sharing customer information that is verified through rational and intuitive processing before it is submitted to pricing systems and outputs are again challenged and sometimes overruled. At DAN Communication, sales representatives' input about customers' willingness to pay are not trusted but are verified and challenged for the discounts that sales representatives want to apply. Request for discounts are evaluated also for coordination purposes so that, for example obsolete inventory and product introductions are taken into account.

The pricing process is therefore not just a structural choice of the optimal allocation of decision rights, deciding which type of cost information to use, or requiring a decision maker to employ a more rational processing of customer information. Rather it is a collective social process in which multiple actors interact and enact practices in order to overcome problems of information, coordination and control. The interlinked practices and activities constitute firms' organization of pricing and regulate the way prices are set.

\section{Notes}




\footnotetext{
${ }^{1}$ Intuition is defined as "affectively charged judgments that arise through rapid, nonconscious, and holistic associations” (Dane and Pratt, 2007, p. 40).

${ }^{2}$ The intercoder reliability test is used to measure the level of agreement between two coders. Intercoder reliability is calculated as the number of agreements divided by the total number of agreements and disagreements. Intercoder reliability adds objectivity and reduces errors (Miles and Huberman, 1994). Miles and Huberman (1994) argued that intercoder reliability should be at least $70 \%$.

${ }^{3}$ Bloomfield and Luft (2006) discussed how responsibility for cost may hinder learning and document that salespeople who do not have access to cost have superior results. In this case, other reasons for reducing the information to salespeople are also important-in particular, coordination issues, discussed below.

${ }^{4}$ The system is a Microsoft Excel tool, internally known as the price calculator. System users can insert the volume and the price being negotiated with the customer into the tool. Among other outputs, the tool calculates the contribution margin to indicate the financial attractiveness of the potential deal.

${ }^{5}$ It may be argued that the micro-level practices are close to being routines. As explained by Reckwitz (2002), in some respects "social practices are routines: routines of moving the body, of understanding and wanting, of using things, interconnected in a practice" (p. 255). While a practice-based approach to the embedded routines may be another fruitful research area for studying this phenomenon, it is beyond the scope of this paper. Rather, our purpose is to study what Schatzki (2002) defined as "doings and sayings" (p. 87) and "bundles of activities" (p. 71). Further, we explore, and advocate for, the practice-based view for pricing process research.
} 


\section{References}

Anderson, J.C., Kumar, N. and Narus, J.A. (2007), Value Merchants: Demonstrating and Documenting Superior Value in Business Markets, Harvard Business Review, Boston.

Artinger, F., Petersen, M., Gigerenzer, G. and Weibler, J. (2015), "Heuristics as adaptive decision strategies in management”, Journal of Organizational Behavior, Vol. 36, pp. 33-52.

Balan, C. (2016), "Delegating pricing authority to the sales force: the need for a turnaround in research and practice”, In A. Hinterhuber and S. M. Liozu (Eds.), Pricing and the Sales Force, Routledge, New York, pp. 172-96.

Baxter, J. and Chua, W. F. (2008), "Be(com)ing the chief financial officer of an organisation: Experimenting with Bourdieu's practice theory”, Management Accounting Research, Vol. 19 No 3, pp. 212-230.

Bloomfield, R. and Luft, J.L. (2006), "Responsibility for cost management hinders learning to avoid the winner's curse”, The Accounting Review, Vol. 81 No. 1, pp. 29-47.

Cardinaels, E., Roodhooft, F. and Warlop, L. (2004), “The value of activity-based costing in competitive pricing decisions”, Journal of Management Accounting Research, Vol. 16, pp. 133-48.

Carricano, M., Trinqueste, J.-F. and Mondejar, J.-A. (2010), “The rise of the pricing function: origins and perspectives”, Journal of Product and Brand Management, Vol. 19 No. 7, pp. 468-76.

Charmaz, K. (2010), "Studying the experience of chronic illness through grounded theory", In G. Scambler and S. Scambler (Eds.), Assaults on the Lifeworld: New Directions in the Sociology of Chronic and Disabling Conditions, Palgrave, London.

Chua, W.F (2007), “Accounting, measuring, reporting and strategizing - Re-using verbs: A review essay”, Accounting, Organizations and Society, Vol. 32 No 4/5, pp. 487-494.

Czarniawska, B. (2007), Shadowing: And Other Techniques for Doing Fieldwork in Modern Societies, Liber and Copenhagen Business School Press, Copenhagen.

Dane, E. and Pratt, M.G. (2007), "Exploring intuition and its role in managerial decisionmaking”, Academy of Management Review, Vol. 32 No. 1, pp. 33-54.

Dörfler, V. and Ackermann, F. (2012), "Understanding intuition: the case for two forms of intuition”, Management Learning, Vol. 43 No. 5, pp. 545-64.

Drake, A.R. and Haka, S.F. (2008), "Does ABC information exacerbate hold-up problems in buyer-supplier negotiations?” The Accounting Review, Vol. 83 No. 1, pp. 29-60.

Dubois, A. and Gadde, L.E. (2002), "Systematic combining: an abductive approach to case research”, Journal of Business Research, Vol. 55 No. 7, pp. 553-60.

Dutta, S., Zbaracki, M. and Bergen, M. (2003), "Pricing process as a capability: a resourcebased perspective”, Strategic Management Journal, Vol. 24 No. 7, pp. 615-30.

Eikeland, O. and Nicolini, D. (2011), “Turning practically: broadening the horizon”, Journal of Organizational Change Management, Vol. 24 No. 2, pp. 164-74.

Ellström, D. and Larsson, M.H. (2017), "Dynamic and static pricing in open-book accounting”, Qualitative Research in Accounting \& Management, Vol. 14 No. 1, pp. 21-37. 
Frenzen, H., Hansen, A.-K., Krafft, M., Mantrala, M.K. and Schmidt, S. (2010), “Delegation of pricing authority to the sales force: an agency-theoretic perspective of its determinants and impact on performance”, International Journal of Research in Marketing, Vol. 27 No. 1, pp. 58-68.

Geiger, S. and Kelly, S. (2014), "Sales-as-practice: an introduction and methodological outline”, Journal of Personal Selling \& Sales Management, Vol. 34 No. 3, pp. 22331.

Gherardi, S. (2012), How to Conduct a Practice-Based Study: Problems and Methods, Edward Elgar, Cheltenham, UK.

Hallberg, N.L. (2017), “The micro-foundations of pricing strategy in industrial markets: a case study in the European packaging industry”, Journal of Business Research, Vol. 76, pp. 179-88.

Hansen, A., Joseph, K. and Krafft, M. (2008), "Price delegation in sales organizations”, Business Research, Vol. 1 No. 1, pp. 94-104.

Hinterhuber, A. (2004), “Towards value-based pricing - an integrative framework for decision-making”, Industrial Marketing Management, Vol. 33 No. 8, pp. 765-78.

Hinterhuber, A. and Liozu, S. (2012), “Is it time to rethink your pricing strategy?” MIT Sloan Management Review, Vol. 53 No. 4, pp. 69-77.

Homburg, C., Jensen, O. and Hahn, A. (2012), "How to organize pricing? Vertical delegation and horizontal dispersion of pricing authority”, Journal of Marketing, Vol. 76 No. 5, pp. 49-69.

Hsu, S.H. (2011), “Cost information and pricing: empirical evidence”, Contemporary Accounting Research, Vol. 28 No. 2, pp. 554-79.

Ingenbleek, P. and van der Lans, I. (2013), "Relating price strategies and price-setting practices”, European Journal of Marketing, Vol. 47 No. 1/2, pp. 27-48.

Ingenbleek, P., DeBruyne, M., Frambach, R.T. and Verhallen, T.M.M. (2003), "Successful new product pricing practices: a contingency approach”, Marketing Letters, Vol. 14 No. 4, pp. 289-305.

Iyer, G.R., Xiao, S., Sharma, A. and Nicholson, M. (2015), "Behavioral issues in price setting in business-to-business marketing: a framework for analysis”, Industrial Marketing Management, Vol. 47, pp. 6-16.

Jarzabkowski, P., Kaplan, S., Seidl, D. and Whittington, R. (2016), “On the risk of studying practices in isolation: linking what, who and how in strategy research”, Strategic Organization, Vol. 14 No. 3, pp. 248-59.

Jensen, M.C. and Meckling, W.H. (1995), "Specific and general knowledge, and organizational structure”, Journal of Applied Corporate Finance, Vol. 8 No. 2, pp. 418.

Jørgensen, B. and Messner, M. (2010), “Accounting and strategising: a case study from new product development”, Accounting, Organizations \& Society, Vol. 35 No. 2, pp. 184204.

Joseph, K. (2001), “On the optimality of delegating optimality pricing authority”, Journal of Marketing, Vol. 65 No. 1, pp. 62-70.

Kahneman, D. and Klein, G. (2009), “Conditions for intuitive expertise: a failure to disagree”, American Psychologist, Vol. 64 No. 6, pp. 515-26. 
Korica, M., Nicolini, D. and Johnson, B. (2017), "In search of 'managerial work': past, present and future of an analytical category”, International Journal of Management Reviews, Vol. 19, pp. 151-74.

Kruglanski, A.W. and Gigerenzer, G. (2011), “Intuitive and deliberate judgments are based on common principles”, Psychological Review, Vol. 118 No. 1, pp. 97-109.

Lancioni, R. (2005), “A strategic approach to industrial product pricing: the pricing plan”, Industrial Marketing Management, Vol. 34 No. 2, pp. 177-83.

Lucas, M. and Rafferty, J. (2008), "Cost analysis for pricing: exploring the gap between theory and practice”, The British Accounting Review, Vol. 40, pp. 148-60.

Lucas, M.R. (2003), "Pricing decisions and the neoclassical theory of the firm”, Management Accounting Research, Vol. 14, pp. 201-17.

Miles, M.B. and Huberman, M. (1994), Qualitative Data Analysis: An Expanded Sourcebook (2nd ed.), Sage, Thousand Oaks, CA.

Nagle, T.T., Hogan, J. and Zale, J. (2016), The Strategy and Tactics of Pricing: A Guide to Growing More Profitably (5th ed.), Routledge, New York.

Nicolini, D. (2009), "Zooming in and out: studying practices by switching theoretical lenses and trailing connections”, Organization Studies, Vol. 30 No. 12, pp. 1391-1418.

Nicolini, D. (2012), Practice Theory, Work, and Organization: An Introduction, Oxford University Press, Oxford.

Nicolini, D. and Monteiro, P. (2017), “The practice approach in organizational and management studies”, In H. Tsoukas and A. Langley (Eds.), The SAGE Handbook of Process Organization Studies, Sage, London.

Reckwitz, A. (2002), “Toward a theory of social practices”, European Journal of Social Theory, Vol. 5 No. 2, pp. 243-63.

Schatzki, T.R. (2002), The Site of the Social: A Philosophical Account of the Constitution of Social Life and Change, Pennsylvania State University Press, University Park, PA.

Silverman, D. (2012), Interpreting Qualitative Data: Methods for Analyzing Talk, Text and Interaction, Sage, London.

Skærbæk, P. and Tryggestad, K. (2010), "The role of accounting devices in performing corporate strategy”, Accounting, Organizations and Society, Vol 35 No 1, pp. 108124.

Spender, J.C. (1989), Industry Recipes: An Enquiry into the Nature and Sources of Managerial Judgment, Basil Blackwell, Oxford.

Stake, R.E. (1995), The Art of Case Study Research, Sage, Thousand Oaks, CA.

Stephenson, R., Cron, W.L. and Frazier, G.L. (1979), "Delegating pricing authority to the sales force: the effect on sales and profit performance”, Journal of Marketing, Vol. 43 No. 2, pp. 21-28.

Van den Abbeele, A., Roodhooft, F. and Warlop, L. (2009), “The effect of cost information on buyer-supplier negotiations in different power settings", Accounting, Organizations and Society, Vol. 34 No. 2, pp. 245-66.

Wilken, R., Cornelißen, M., Backhaus, K. and Schmitz, C. (2010), "Steering sales reps through cost information: an investigation into the black box of cognitive references and negotiation behavior”, International Journal of Research in Marketing, Vol. 27, pp. 69-82. 
Zbaracki, M.J. and Bergen, M. (2010), “When truces collapse: a longitudinal study of priceadjustment routines”, Organization Science, Vol. 21 No. 5, pp. 955-72. 